\title{
Clinical Trial Subject Miscellaneous Form
}

National Cancer Institute

\section{Source}

National Cancer Institute. Clinical Trial Subject Miscellaneous Form. NCI Thesaurus. Code C115518.

Documentation, which is not otherwise classified, that is given to a subject in a clinical trial. 